Alceu de Arruda Veiga Filho; Tamás Szmrecsányi; Pedro Ramos. "IMPACT OF THE SUGAR-ETHANOL SECTOR:

THE ISSUES GUIDING SUSTAINABLE EXPANSION", p.279-290. In Luis Augusto Barbosa Cortez (Coord.).

Sugarcane bioethanol - R\&D for Productivity and Sustainability, São Paulo: Editora Edgard Blücher, 2014.

http://dx.doi.org/10.5151/BlucherOA-Sugarcane-SUGARCANEBIOETHANOL_28

\title{
IMPACT OF THE SUGAR-ETHANOL SECTOR: \\ THE ISSUES GUIDING SUSTAINABLE EXPANSION
}

\author{
Alceu de Arruda Veiga Filho, Tamás Szmrecsányi and Pedro Ramos
}

\section{INTRODUCTION}

\section{Raising the pressing issues of development of the sugar-ethanol industry}

The economic and social development of a country or a region does not proceed, or is only assessed in quantitative terms, but primarily in quality. Within this last perspective, there is not any objective reason for the State of São Paulo to have more than half of the sugar plantations of the country. Sugarcane is the main crop that occupies the largest cultivated land area in São Paulo. Everything indicates that these are distortions and irrationalities that to be fought on behalf of technical progress, harmony and a balanced environment; there is a need for land decentralization of land, increased and diversified crop production in the State.

In context, we are experiencing an expansion phase of the alcohol market, internal and external, which has led the State of São Paulo to occupy - according to data from the 2006/07 season, to 5.5 million ha with sugarcane, responsible for approximately $60 \%$ of domestic production of sugar and ethanol.

What are the potential impacts of this growth? Selected issues relating to concentration of land and an environmental impacts, labor relations, and competition with other factors of production, indicate that it can create difficulties to the productive system.

These problems cannot be solved by the free market forces alone, but require the active inter- vention by the state and various federal government agencies.

Starting with the land issue, we know that the main feature of the installation of plants is through the incorporation of land owned or leased, to ensure the supply of raw material. In São Paulo the average agricultural area of sugarcane plantations in the 1970s was 8,000 hectares, and is currently around 12,000 ha, and the areas of independent suppliers have remained virtually the same over the past 30 years; that is, between 12 and 45 ha.

Studies on the distribution of cultivated sugarcane planted area show that between the periods $1995 / 96$ and 2002/03, the average area was 31,000 thousand hectares in 2002/03, up 9\% from 28,500 ha of $1995 / 96$. These studies also show that sugarcane growers with less than 1,000 ha fell by $21 \%$ with an average reduction of 476 ha to 376 ha.

This form of concentration is what is occurring in the new areas of expansion in the west of the state, either in the form of leases and land purchases. One consequence of this land concentration is the disruption of other social and productive activities which may be less attractive than sugarcane, but important locally. Small producers associations, with long historial tradition and deep local social and economic roots can be broken by the impact of local expansion of sugarcane.

Another consequence of this rapid expansion is the removals of other land uses, groves, hedges, fences and any other obstacles that impede largescale sugarcane plantations. Furthermore, small farmers, who leased or sold their land, hardly come 
back to farming because they usually sell their machinery and equipment and migrate to the cities. This has already occurred during the first phase of the Proálcool in Brazil (Brazilian National Ethanol Program), back in 1970s and 1980s.

There are also serious environmental issues e.g. those posed by sugarcane burning, the destruction of riparian forests, water sources, and correct application of vinasse and pesticides utilization and their impacts. All of these issues require careful environmental management.

It is well known that sugarcane burning can caused serious environmental damage e.g. on soil microorganisms subjected to extreme heat causes, death of animals, enormous waste of energy contained in the cane trash, loss by exudation of sugar in the stalks burned, increases pollution impacts on human health etc. It also leads to increase water consumption in urban areas as water has to be cleaned up of residues deposited by burning; and also from in houses, yards and service areas. But one the most serious is in health cuased by increases in air pollution.

For the forests and protection of water sources, despite the legislation, there is still much to learn. For example, official surveys during the 1970s compared with today, show the elimination of many water springs that have been dried up by pumping water for irrigation, including sugarcane.

The regulations on the use of vinasse, according to São Paulo State Environment Agency - CETESB 2005, for use in areas near and has proven saturated, is proof that although the organic byproduct vinasse is mostly water and nutrients, their use must be controlled because it can lead to the salinisation of groundwater by leaching of these elements, and also cause nitrification of the soil and contaminate groundwater. Studies need to be conducted with much rigor to properly evaluate the problem.

There is the danger of contamination of aquifers, which are underground reserves of fresh water, from herbicides, pesticides and chemical fertilizers. In this case, the concern is that sugarcane is grown around areas of major aquifers in the region of Ribeirão Preto and Jaú / Bauru. This requires careful monitoring with equipment that provides information about contamination analysis and other surveillance measures.

Among the issues selected for debate and discussions, is the issue of labor relations. Although there is demonstrated progress on the formalization of contracts and the abolition of child labor in the State of São Paulo, there still remains problems of compliance with NR 31 (safety and health), and fair payment according to the production of sugarcane harvested. The latter is responsible for the overexploitation of labor in the industry, and has resulted in extreme suspicion of death by exhaustion, as reported in the press and commissioned by the Labor Attorney.

Of course, it is well known the difficulty in complying with the legislation because there will always be ways to by-pass it e.g. to establish production goals accurately strick monitoring by labor unions, and supervision of the officers.

There has been an intense debate on the impacts of ethanol on food prices. In the majority of cases such price global demand for biofuels to meet the increased supply of energy while reducing the use of nonrenewable resources and emitting carbon dioxide, this question becomes strategic, also considering the importance food security, starting to intensify the competition for productive resources, credit and subsidies. This, of course, raises the need to identify the problems derived from competition between them and the need to consider mitigation solutions.

Therefore, we highlight these four crucial aspects to compose a research program to study the evolutionary process of the sugar-ethanol industry: the labor question, the issue of land concentration, environmental issues and the question of the impact on food prices.

This analysis is concerned to: a) current situation, b) existing bottlenecks, c) prospects for the sector development in scenarios with and without structural changes, and d) finalize with the demands of research projects that will mark out public policies business strategies more efficient and sustainable. 


\section{Discussion about land ownership Issue}

Study the concentration of land as a process that establishes a logic of economic and social characteristics of the sugarcane agribusiness in Brazil is important to properly discuss the economic and social benefits that the expansion would bring. This has been overlooked by prospective studies of the expansion of such agribusiness industry in Brazil.

This logic is the same for the new areas, and it is not small the projected expansion: it is expected that over the next five years no fewer than 77 new production units are built to expand the supply of Brazilian ethanol and sugar, and 35 of them in São Paulo State, 18 in Minas Gerais State, Goias State 10, 9 in Mato Grosso do Sul State, Paraná State and 4 in 1 in Rio de Janeiro State.

Notice that for three moments in the recent period, i.e. 1984/5-85/6 - 1996/7-97/8 and 2005/6-06/7, it was clear that it can be considered as the main manifestation of concentration that characterizes the sugarcane agribusiness in Brazil, namely, to crush predominantly the raw material produced by own factory owners and owners of distilleries in their lands or agricultural establishments.

The increase in the percentage of sugarcane itself in the Central / South between 1985 and 1996 shows that the expansion of sugarcane industry to the states of Central and Western was based on estates formerly formed, and / or alumni linked to the establishment of factories were built by local landowners, or who migrated to the local states. The drop in this percentage between 1996 and 2006 should be viewed with caution, because of what is hereinafter pointed out. However, one can not emphasize a real fall, because the plants as they are being extended, require larger amounts of sugarcane, which usually involves the addition of new cane suppliers. The case of Mato Grosso State is in an example.

Another aspect of concentration can be observed by the systematic information of the raw material source crushed by plants between the periods 1995 / 6 to 2002 / 3. It is possible to highlight two aspects: first, that the average area harvested own by the mill / distillery has evolved into more than five thousand hectares in just seven years, and secondly, that such a development focused on units that already had larger average areas, i.e., the stratum with more than twenty thousand ha.

Another manifestation of the concentration of land underlying the production of cane can be drawn based on data relating only to the supply of cane to the mills and distilleries. The data, which yields the 1995/6, 2004/5 and 2005/6 show that the great expansion that has occurred in São Paulo has been accompanied by a concentration of sugarcane production in the major suppliers/ producers, despite the existing high number of them, the percentage of suppliers that provide more than ten thousand tons per year rose from 53.2 in 1995/6 to 64.9\% in 2005/6 having decreased the percentages of all other strata.

The situation existing today can be changed and, moreover, to refrain from getting worse, are pointed out two sets of public policy measures that can be adopted.

The first is general and concerns the need for change in legislation and land policy. It can be argued that few countries have the world's land law as permissive as that of Brazil, there is no restriction on the use of land. To use a fashionable term, the "governance structure" linked to the land issue in Brazil needs to be dramatically changed.

The second one is related specifically to the modus operandi of the agents of the economically strongest cane agribusiness in Brazil, which, given the legal framework allows for the configuration of your current structure. This was a matter of concern for the status of sugarcane crop of 1941, but he was being, especially in São Paulo and after the Second World War, disrespected and openly contradicted by decree in late 1960 and today is totally ignored, although it is a law that has never been repealed entirely. The issue is how to discipline the sector as far as the cane produced by the plant can be milled and establish other rules (regarding prices, forms and criteria for payment, ensuring grinding etc.) regarding the supply of cane for independent producers and their associations. 
As noted, the indications are that the main characteristic of the land base of our sugarcane agro-industry remains in expansion, and this is the feature that promotes exclusive ownership of income and, thus, contributes greatly to increase the concentration of wealth that has marked the history Brazil.

Demands for research on land issues:

- Comparative studies of sugarcane production in the various situations of land ownership (Australia, South Africa, USA - Florida, Brazil - NE and CS).

- Studies on concentration of land and income.

- Studies on replacement of the cane on other activities and the impacts.

- Studies on the regulatory role of the state in land use and spatial alcohol sector versus the political power of the alcohol sector.

- Studies on the pricing and distribution of the benefits of by-products between plants and suppliers.

- Studies of economic viability of non-vertical structures of raw material versus the vertical structure of existing production.

- Studies on the formation of economic groups and their business strategies.

\section{Discussion on the issue of labor relations}

The present study examined the socio-economic profile of jobs in the sugar-ethanol industry, using information from the governamental employment register (CAGED) of the Ministry of Labor and Employment for the years 2006 and 2007. This source contains monthly data on the total number of accepted and off by economic activity, as well as variables that allow diagnosing the socio-economic profile of workers by occupation, geographic etc.

The analysis involved five groups of occupations according to the Brazilian Classification of Occupations (CBO2002): agricultural workers (involving cane cutters), supervisors, tractor, other agricultural occupations (except cutters) and other non-agricultural occupations (managers, secretaries, drivers etc.).
The sugar-ethanol sector in CAGED is defined within the activities of the National Classification of Economic Activities (CNAE95) IBGE, namely the cultivation of sugarcane (agricultural sector), service activities related to agriculture (agricultural sector), sugar mills (industry), refining and milling of sugar (industry) and alcohol production (industry).

The category of workers that involves cutters accounts for about $70 \%$ of hires made in 2006 and 2007, with a slight decrease last year (2007).

What is observed is that regardless of occupation, and more strongly to the cane cutters there is a strong seasonal hiring. There are a large number of persons admitted during the harvest at the end of which is dispensed. The resulting balance between admitted and dismissed in addition to being low for the year 2007, decreased considerably compared to 2006.

For the socio-economic variables present in the CAGED was found that there are great differences in age, educational level and gender of the sugarcane cutters in relation to the other workers groups. The cutters are younger people (better productivity), while tractor operators, for example, are people with older age (more experience). It is observed also that the cutters and other agricultural occupations have less education as compared to tractor drivers and other non-agricultural occupations. Thinking in terms of relocation of the cutters, the quicker and easier would be to relocate to other agricultural functions.

The main concern from the social point of view, is whether there will be time for the retraining and relocation of cane cutters for other functions, either in the alcohol sector, or in other agricultural activities according to the progressive increase in the mechanization of cane harvesting and the mechanization of the agriculture as a whole.

In order to measure the impact of mechanization on workers employed in the harvesting of sugarcane it was estimated a rate of mechanization in the harvesting of sugarcane. With this parameter, and others also obtained for the harvest of 2007/08, as production of sugarcane (3.2 million $t$ ) and the 
amount of sugarcane harvested by a man in a day (8.76 t/day) and 132 days actually worked in the harvest, it was estimated that about 160 thousand people were involved in cutting sugarcane in São Paulo. This means it will be replaced around 2,700 cutters if the mechanization index increases 1\% per year.

Demands for research on labor relations:

- Studies on the profile of the labor force employed in sugarcane.

- Studies on first job.

- Studies on layoffs.

- Studies of gender and age of the labor force.

- Studies on child labor.

- Studies of occupation in other agricultural activities and non-agricultural labor force employed seasonally in sugarcane.

- Studies on impacts of mechanization of planting and harvesting in labor relations.

- Studies on migration.

- Studies on impacts of crop productivity in health.

- Studies on the costs of mechanical harvesting x manual harvesting.

- Studies on land use and social occupation of land.

- Studies on the payment system for crop production in the sugarcane.

- Studies on industry competitiveness and the role of labor costs (wages and occupation).

- Studies on demands in their own employment-agricultural sector and other sectors.

- Studies on the payment of cane by productivity.

\section{Discussion on environmental issues}

Despite the favorable economic situation in which it is the sugarcane activity in recent years, the role of sugarcane production in regional development has been a much debated in the state of São Paulo. While sugarcane agribusiness seeks to highlight the international market, from the image of a clean production and been environmentally correct, that would be consistent with the environmental sustainability of the planet, workers and local communities who live with the system of production of sugarcane. However, there is another reality, marked by social problems and environmental problems, closely related to a chronically neglected with respect to environmental standards of the country.

If on the other hand, the production of alcohol from sugarcane contributed to the reduction of carbon emissions and the elimination of lead tetraethyl use in the fuels, with positive effects on air quality in large cities, contributing to reduce the greenhouse effect, on the other hand was highly pollutant in areas where it was produced.

This is shown by the aspects related to monoculture, which also negatively affect biodiversity. This has brought the need for intensive use of chemicals that pollute rivers, groundwater, soil, and cause imbalance of agroecology, and the practice of open field burning for the elimination of straw, which affects air quality, destroy soil microorganisms and fauna within the forest, and by pouring the vinasse and cane wash water in the rivers, which led to siltation and fish mortality for many years until the emergence of an alternative use for these wastes.

With regard to progress on environmental preservation areas, the data show that of 18.9 million hectares of farmland in the State of São Paulo, 4.4 million should be dedicated to environmental conservation, or preservation areas and legal reserves. However only 700 hectares fulfill this function, resulting in a debt of 3.7 million hectares.

Most historically "sugarcane" municipalities the state of São Paulo, as Barrinha Dumont, Guariba, Jaboticabal and Pradópolis, currently have less than $1 \%$ of natural vegetation, showing a direct relationship between the sugarcane monoculture and degradation of ecosystems. Areas of Permanent Protection (APP), which comprise the set of riparian forests, forests of slopes, headwaters of rivers and springs, defined by the Brazilian Forest Code, were extremely devastated by the expansion of plantations, and only began to be recovered thanks to the pressures State and the prosecutor, although in a very incipient maner. 
Still, the evacuation of areas of Permanent Protection for reforestation has occurred at the expense of relocating the cane to areas occupied by other cultures, again focusing on reducing the state's agricultural diversityIn the other hand, the Legal Reserve Areas (ARLs) as defined by the forest code as areas located within a rural property or possession (excepting the permanent preservation), necessary for the sustainable use of natural resources, conservation and rehabilitation of ecological processes, the conservation of biodiversity and the shelter and protection of native fauna and flora, were virtually extinct in the land where grown sugarcane.

Researches conducted in several plants and sugarcane farms in the state, could not identify even one production unit that maintained legal reserve areas in farmland. In all these cases, when questioned about the problem, farmers and plantations owners proved to be outraged and adamant about any argument, stating that the maintenance of legal reserve areas for economically infeasible agricultural production in those properties.

Other issues stand in the relation between the current system or model of sugarcane production and the environment, such as the use and contamination of water resources, large-scale pesticide use, and use of fire.

The first point concerns over the impacts of sugarcane production on water resources refers to one of the most bulky waste generated in the process of obtaining alcohol: the vinasse, also known as stillage. The vinasse is produced at a rate of approximately 13 liters for every liter of alcohol produced. It consists mainly of water, salts, suspended solids and soluble. Because it is one of the most polluting waste and corrosive acids, which resists any kind of treatment usually used for other industrial waste, given their chemical characteristics, the search for an appropriate destination was one of the biggest challenges for the sector. Until the discovery of their potential as soil fertilizer in the mid-1980s, this waste was commonly disposed of in rivers or sacrifice areas, causing serious pollution and fish kills, and nuisance to the neighborhood caused by the bad smell of residue.
When not treated, the stillage becomes a dangerous pollutant, because the aerobic bacteria present in the juice voraciously consume the oxygen of the water, killing life in rivers. The stillage may be disposed in sacrifice areas, usually large storage tanks of the product. In this case, the environmental damage can be given to the contamination of groundwater and its overflow, which threatens the rivers.

Furthermore, when used properly, the stillage is transformed into a powerful organic fertilizer. The form of distribution and quantity of waste applied in the field, as well as its composition vary greatly from plant to plant, which makes it very worrying. Research has indicated that the areas of raw cane can absorb more liquid than the areas where burning is practiced. However there are few plants that have considered this fact in the application of liquid waste in the field, which means that there may be contamination of underground water and aquifers, not only by the waste, but also by pesticides and fertilizers, on the surface of the soil, and are carried into the subsurface.

Seeking to give more specificity to this issue in April 2005 CETESB issued a regulation, reissued in December 2006 (P4.231) defining the criteria and procedures for storage, transport and surface application of vinasse on the ground state of São Paulo.

In this regulation has been established the obligation to submit a "Vinasse Disposal Plan", until April $2^{\text {nd }}$ each year, containing maps and the identification of application areas, channels, tanks, data on land, forms and dosages application, as well as chemical characterization of vinasse to be used (based on the previous season).

Another problem, the use of pesticides in plantations, although it does not seem dangerous, it represents a high risk to the environment, for its interference in ecological systems, and also on the health of local populations by contaminating water. To get an idea of the size of the problem, most of the inhabitants of the municipalities sugarcane consumes water collected from rivers in the region whose treatment does not retain such toxic substances. Other part receives water from 
aquifers whose recharge areas are in fact covered by cane fields.

Even with the advances obtained in the research field, which has enabled the replacement of many pesticides by alternative methods to control pests and diseases, such as breeding, biological control of pests and the production of insecticides, the use of some classes like herbicide remains high.

Recent studies show that persistence in the soil of the main herbicides used in sugarcane plantations in the region reach even two years, representing a high risk of contamination of rivers, groundwater and underground aquifers. Although there are alternative techniques for the management of weeds, few measures have been observed to reduce the use of such pesticides in the field.

Another problem, the practice of straw burning of cane fields, a solution was found in the past to resolve the issue of increasing the area planted with sugarcane without considerable increase in the cost of the labor force. A practice that has become customary in the majority of farms dedicated to its cultivation, with the main objective to facilitate and lower the cutting sugarcane costs by hand, being used even the mechanical cutting (within the so-called Australian method).

The use of fire as an agricultural practice in the sugarcane has a long time been condemned by experts in various fields, including engineers, biologists, scientists and doctors, despite the vehement opposition of technicians in the industry, claiming that such a practice facilitated the harvesting process, generate jobs, bringing security to the rural worker, and did not interfere negatively on the environment, because it is a fast, localized and controlled, and is still present in the speech of some entrepreneurs in the industry.

A number of studies were conducted warning about the serious risks that the burning of sugarcane has represented to human health. There are various respiratory problems caused mainly by organic compounds generated by combustion of straw, such as polycyclic aromatic hydrocarbons (PAHs), highly carcinogenic compounds, which are found among the gases that make up the "smoke" from burning cane fields.
The effects of burning cane fields before harvest, under the entomological point of view, is a modern subject, because the sugarcane agroecosystem is composed of many arthropods that play an important role in pest control and assisting in the decomposition and mineralization of soil organic matter.

Despite the fact that fire removes much of the insect pests, it also eliminates most of their natural predators, such as the Amazon fly and Cuban fly, which fight the sugarcane borer (Diatrea saccharalis) the major pest of this crop, causing ecological imbalance, which in turn necessitates the use of pesticides.

Although the fire is fast, because of all the preparation done in the cane fields before the fire, it is enough to destroy a still unknown number of species of fauna, from insects to larger predators, causing an ecological imbalance even greater than the practice of monoculture plantation.

The heterogeneous reality of the sector shows that the technology is perfectly capable of reducing environmental problems involving this production model marked by monoculture, by field burning and the use of agrochemicals.

However, the facts show that economic change has been possible only by the pressure exerted by the state and society in the sense of law enforcement, because of the importance of this sector, is that the economic advantages offered by the disrespect some environmental standards, as is the case of APPs, Legal Reserve Areas and the standardization of fire, still outweighs the benefits of ethical behavior to the consumer.

Demands for research for the environmental issue:

- Studies on impacts of fires on human health.

- Studies on effects of gas concentration by the use of fire.

- Studies of alternative techniques for the treatment of vinasse pollution and impacts on water resources by using this by-product non-treated.

- Studies on impacts on flora and fauna of the burning cane. 
- Studies of alternative regional production systems of sugarcane in order to recover the legal reserve areas, APPs, riparian and watershed protection.

- Comparative studies of technical and economic methods of biological control and conventional control.

\section{Discussion of the cane and its influence on food prices}

The causes of the recent rise in food prices in 2008 in Brazil transcends the impact of sugar and alcohol production, because it is likely the structural sense, not just cyclical and is probably a trend driven by different forces, converging to, by different ways, generating an upward price cycle. This, now it is driven by external variables, but has a high probability of further fueled by internal factors.

These two factors sets (Asian demand and oil prices) would be able to produce short-term external inflationary pressures on food prices, as we faced in 2008, but not likely that this tension is continuously fed the same factors that propel the moment, unanswered production and trade over time as the cushion. The economic history is rich in revealing reversal of growth cycles in prices, changes in production techniques that fundamentally changed circumstances of particular markets and many other situations of innovation that eventually alleviate the inflationary pressures from oil and / or agricultural commodities.

But the cyclical tension on food prices in the Brazilian can become a structural problem for price stability or economic growth (or both), depending on the adjustment process of economic crises of the commodities that we follow. In this sense, there is evidence that Brazil has been pursuing a structural-adjustment in the Current Account Balance of Payments, where the export requirements of "food-grains", "feed-grains", "meat", products of forestry, agro and mineral products have become essential to compensate for the structural imbalance of the "Account Services" and the international trade in manufactured goods of higher technology.
That said, from agriculture and mining would be required in the next decade a growing of exports higher than output growth of these sectors (manufactured goods of higher technology) in order to gain positions in world trade - mainly in these supply chains.

Physical growth of agribusiness exports occurs at rates almost double the production growth in the period 2000-2008, and almost three times compared with domestic consumption, evidence that is taken as the trend continued, would certainly cause problems to domestic supply.

On the other hand, if you look at the projected future growth of production, consumption and exports of these products, we see that the trend of the previous period, on two fronts: a) production and consumption of cereals and grains direct human consumption grow at rates very low, below the population growth, and b) meat (beef and chicken), feed-grains (corn and soybeans) and alcohol, have projected export growth rates of twice the domestic consumption.

Inflationary pressures to which we refer in the beginning, tend to worsen if the pace of growth of production, consumption and exports in the coming years remains the same pattern observed in the seven previous years.

But the issue that now concerns, the impact of the exporter boom of commodities in food prices, is possible that the economic policy to seek new incentives for exports as the primary means of addressing the current account, even if the situation of deficit persistent and strong. This strategy certainly does not alleviate, but likely increases pressure on food prices.

However, there is evidence (that it is not shown here), that the Balance of Payments Account Services has expanded its deficit trends, particularly since 2004 when the economy showed signs of growth. That said, it seems likely that the next decade the export policy at all costs implemented in the period 2000-2008, is recalibrated and pursue the same trend in exports, production and consumption of food, "feed-grains"; meat and ethanol, to pursue the last seven years.

The economic situation (period 2000-2007), although pursue the same goal of adjustment of 
1982/84, suggests a structural orientation to a certain specialization of foreign trade competitiveness of the primary sector. If this hypothesis is true the consequences tend to be worrying about the price of staple foods.

Thus, it seems that there are several lines of economic policy (not just one isolated policy to promote the replacement energy), which converge in the same direction as the significant increase in net export of primary sector in order to fill a role in mitigating the structural deficit of the external transactions of the country The implications of this policy have the following potential implications for what interests us here focus on:

1. Pressure on food prices, even in a situation of high exchange rate appreciation, as in 2008, this pressure is weakened by an environment of rising prices of foreign commodities.

2. Show the same trend is inflationary changes in exchange rate policy significantly alter the degree of recovery of the real exchange rate (to lower) the result of some broader policy of adjusting the Current Account of Balance of Payments.

3. In any of the above (1 and 2), management policies of inflation through interest, as has been the tendency of the Brazilian Central Bank, run to cut the growth in domestic demand and GDP, without affecting the specific causal focus on inflation real reasons.

4. The boom exporter shape especially in the production of feed-grains (soybeans and corn) and sugarcane crop in the year 2007 census, affecting the whole $55.8 \%$ of the crop. Meanwhile, as the exporter bias is also present in the cattle industry and the pulp and paper, should occur between these sectors intense competition for use of the exploitable area, with consequences of strong appreciation and speculation about the price of land.

5. It is inevitable that the expansion combined of feed-grains, sugarcane, livestock and plantations for pulp and paper, to the rhythm that requires them to consider the external accounts - exert strong pressure by the addition of new areas of culture crops. Just note that between 1995 and 2006 (planting dates of their agricultural censuses) the expansion of crop areas was 34.9 million hectares (83.5\% in eleven years), which means the annual rate of increase of $5.7 \%$ per year on average.

6. There is evidence that the expansion of the sugarcane as a paradigm of what happens in other agro-export chain, with the features now described happens with falling occupancy of the workforce, because the heavily mechanized production processes adopted. But even when these processes have not yet been adopted - the case of cane-hand cutting conditions are overexploitation, with severe consequences for the morbidity of the workforce.

7. The various consequences of setting the Balance of Payments by the primary sector, with the election of specific alcohol sector to star in a World Proálcool-configure a pattern of "reprimarization" of the Brazilian economy, characterized by increase in social inequality. It also reveals the possible effects of inflation, which antidotes of economic policy in consistent use by the Central Bank cut every incentive to spread in domestic demand.

8. Ultimately, the model set by the export of primary Balance of Payments becomes the explicit strategy to transfer the "net income sent abroad" in liquidity crises. When the external liquidity is loose, this primary-export policy, act as guarantor for the management of the deficit "Account Services" until the next crisis of liquidity outside of the Balance of Payments.

\section{Demands for research on the issue of impacts} on prices:

- Studies on the U.S. policy of ethanol that directly impacts food prices worldwide.

- Studies on the deepening of protectionist agricultural policies of developed countries.

- Studies on the role of reprimarization of exports and inflation effects arising. 


\section{FINAL CONSIDERATIONS}

It is our belief that a first and important contribution is the fact that the workshop participants have debated and raised questions for discussion by scholars and police makers. This group is not far from the concept of stakeholders, and comprising relevant actors of the context.

Although in many measures, seems to point problems and their causal relationships is to say what should not, want to be away from this moralistic view on the premise that the complexity of economic and social forces to ever break even for researchers The attitude of commitment to equitable development of humanity, and last main body to be pursued (which is no longer a profession of faith, so full of ethical content), but always mark out the analysis for comparison of theory and facts in his light.

On the land issue must be pointed out two sets of policies: the first is general and concerns the need for change in legislation and land policy. It can be argued that few countries have the world's land law as permissive as that of Brazil. The second one is related specifically to the modus operandi of the agents of the economically strongest sugarcane agribusiness in Brazil, in the case of the need for discipline regarding the cane owned by the mill itself. It can be milled, as well as define other rules in respect of the provision of sugarcane by independent producers and their associations.

After all, the indications are that the main characteristic of the agrarian base of our sugarcane agro-industry remains extended, and it is the feature that promotes exclusive ownership of income and, thus, contributes greatly to increase the concentration of wealth that has marked the history of Brazil.

From the social point of view on the issue of labor and employment, given the speed with which we see the reduction of occupation by the substitution of machine harvesting sugarcane, the main concern from the point of view, is whether there will be timely for retraining and relocation of cane cutters for other functions, either in the alcohol sector, or in other agricultural activities according to the progressive increase in the mechanization of cane harvesting and mechanization in general own agriculture.

Therefore, it is urgent not only to draw public policies aimed at retraining workers, but it should think, at least at minimum revenue policies for those who may not have better conditions of employment or retraining.

On environmental issues, in turn, the facts show that the economic change from the side of environmental sustainability has been possible only when there is pressure from the state and society towards the enforcement of laws, because what we notice is that the economic advantages offered by the disrespect some environmental standards still override the benefits of ethical behavior to the consumer. Moreover, one should not forget that there is always pressure on the side of the external market, so there is demonstration of mitigation on the side of environmental sustainability.

Finally, upward pressure on food prices by the expansion of sugarcane, the angle of macroeconomic analysis can be analyzed through the various consequences of the adjustment of balance of payments and this leads to consider the nature of the problem as being much more structured than cyclical, since the reprimarization the Brazilian economy and the need to revise the standard.

The analysis conducted on these four topics listed possible to derive findings and conclusions referenced above and also from them one can deduce a number of needs for research studies, composed of:

1. Studies on the regulatory role of the state in land use and spatial alcohol sector vis a vis the political power of the alcohol sector.

2. Studies on economic viability of non-vertical structures of raw material versus the vertical structure of existing production.

3. Studies on the formation of economic groups and their business strategies.

4. Studies on the impact of mechanization of planting and harvesting in labor relations.

5. Studies on the payment system for crop production in the sugarcane.

6. Studies on alternative processing techniques vinasse pollution and impacts on 
water resources by using the by-product non-treated.

7. Studies on alternative regional production systems of sugarcane in order to recover the legal reserve areas, APPs, riparian and watershed protection.
8. Comparative studies on technical and economic methods of biological control and conventional control.

9. Studies on the deepening of protectionist agricultural policies of developed countries.

10. Studies on the role of reprimarization of exports and inflation effects arising. 
